mgr inz. Karol Bryk

mgr inz. Krzysztof Lukaszewski

Instytut Pojazdów Szynowych "TABOR”

\title{
Spectral analysis of accelerations measured on a passenger car as a fault-detection technique
}

\begin{abstract}
This paper presents a dynamic simulation study of a passenger car. The passenger car is equipped with a standard Polish bogie 25ANa. The bogie 25ANa has been designed by Ryszard Suwalski [1].

Spectral analyzes performed to detect damage to the vehicle suspension. In studies used a multi-body, dynamic calculation system SIMPACK 9.5. All analysis presented here are based on the standard wheel-rail profile combination S1002/UIC60, the rail inclination 1/40. The accelerations from the dynamic simulation used to calculate and create spectral markers. Spectra calculated using the Fourier transform
\end{abstract}

\section{The model of a railway vehicle}

The model reflects the structure of a typical passenger car operated on railway routes in Poland. The mechanical model of the vehicle consists of rigid bodies connected by elastic elements represented by links between solids on Fig. 1.1. shows the schematic interconnectedness of the vehicle kinematic rigid bodies.
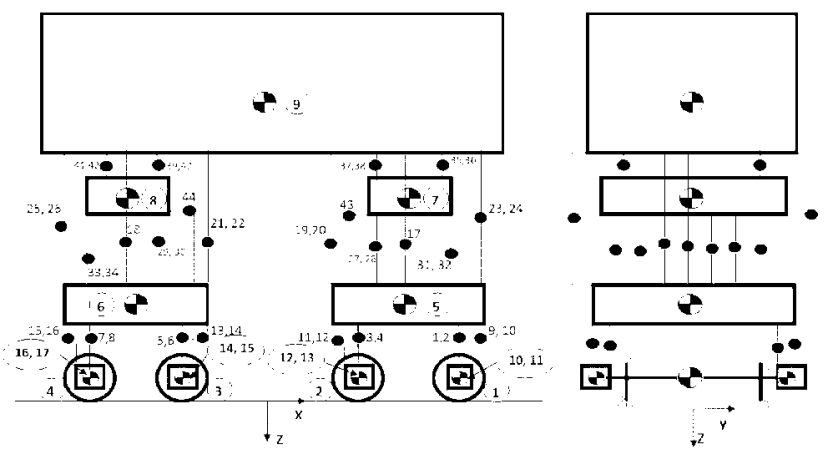

Fig. 1.1. Diagram of a mechanical vehicle model

The simulation was carried out in SIMPACK 9.5 system which is currently one of the leading systems used to simulate the dynamic behavior of the rail vehicle. Simulation studies were conducted on the composition model (Fig. 1.1), which consists of two complete bogies (Fig. 1.2) and a car body.

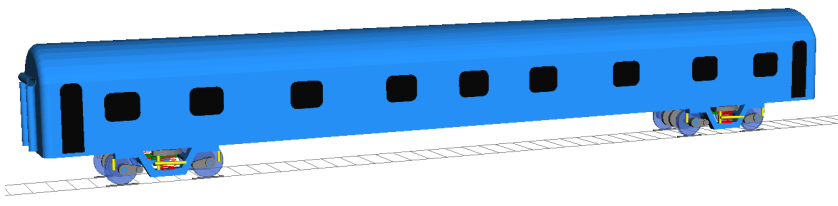

Fig. 1.2. The full model of passenger car executed in the program SIMPACK
Table 1.1 shows the modes of vibration of the model.

Table. 1.1. Natural frequencies and modal damping of the model

\begin{tabular}{|c|c|c|c|c|c|}
\hline \multirow[b]{2}{*}{ Number } & \multirow[b]{2}{*}{ Mode } & \multicolumn{2}{|c|}{ Empty car } & \multicolumn{2}{|c|}{ Loaded car } \\
\hline & & $\begin{array}{c}\text { Frequencies } \\
\mathbf{f}[\mathrm{Hz}]\end{array}$ & \begin{tabular}{|c|} 
Modal \\
damping \\
d [\%] \\
\end{tabular} & $\begin{array}{c}\text { Frequencies } \\
\mathbf{f}[\mathrm{Hz}]\end{array}$ & $\begin{array}{r}\text { Modal } \\
\text { damping } \\
\text { d [\%] } \\
\end{array}$ \\
\hline 1 & $\underset{z y}{0 j 0}$ & 0,49 & 0,14 & 0,44 & 0,12 \\
\hline 2 & $\underset{y r}{\stackrel{H}{H}=\underbrace{H}_{-} x}$ & 0,90 & 0,48 & 0,81 & 0,42 \\
\hline 3 & 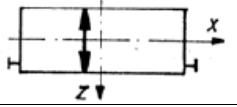 & 1,13 & 0,16 & 0,99 & 0,14 \\
\hline 4 & 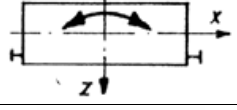 & 1,43 & 0,20 & 1,27 & 0,18 \\
\hline 5 & $\underset{z 1}{\rightarrow \rightarrow 0}$ & 1,48 & 0,47 & 1,33 & 0,41 \\
\hline 6 & $\frac{f}{t i}$ & 7,48 & 0,46 & 7,50 & 0,48 \\
\hline 7 & $t \stackrel{4}{\rightarrow}$ & 9,82 & 0,45 & 10,10 & 0,45 \\
\hline
\end{tabular}

\section{Description of the research methods}

In order to test the possibility of using a signal coming from the accelerometers located on the vehicle to diagnose suspension condition, there have been made several series of simulation rides of vehicle in different condition. In particular rides the selected secondary suspension dampers have been turned off, what simulated their failures. Since it is vital to obtain an effective diagnostic regardless of the track and the vehicle speed, the simulation has been 


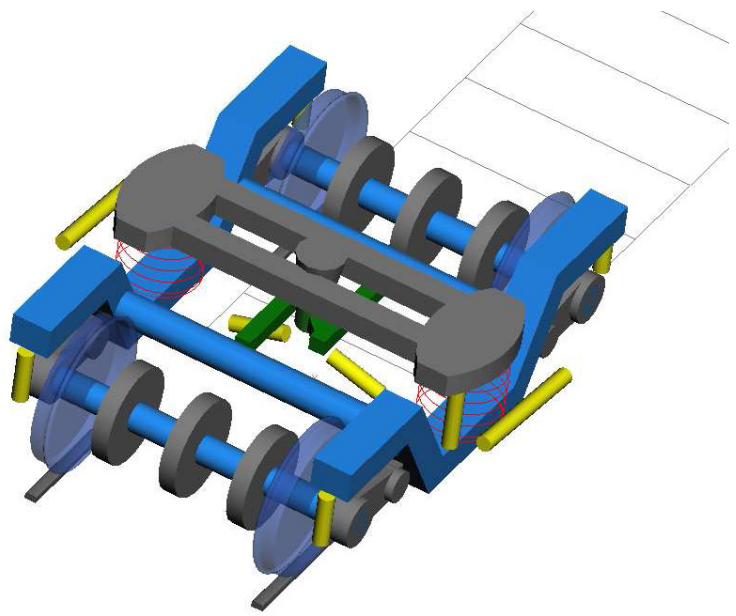

Fig. 1.3. The full models of bogie $25 \mathrm{ANa}$ executed in the program SIMPACK

performed with different track sections inequality and the runs were simulated at the different speeds. Location of accelerometers on the vehicle has been shown in the fig. 2.1. Two accelerometers are located on the car body directly over the bogies of the vehicle, the next two are installed in the middle of the bogies frames. These four sensors are intended to diagnose the faults in secondary suspension dampers.

Since the accelerations of the vehicle body are dependent on the track inequalities, therefore reliance only on acceleration spectrum measured on car body does not guarantee the sufficient efficacy failure detection. It seems to be more effective to compare the acceleration spectrum from the vehicle body with acceleration spectrum from the axle or the bogie frames. That provides at least approximate information about extortion from the irregularity of the track. In this case in order to observe the state was decided to use the relationship between acceleration spectrum of the vehicle car body and acceleration spectrum on the bogie frame located under sensor on the car body. This solution is designed to ensure the effectiveness of fault detection regardless of the state of the track and speed. The method described above does not include the phase difference between the extortion between the first and the second bogie. For example: if vertical extortions on both bogies have the same phase, the car body vertical oscillation is without rotation. But if extortion between the bogies is offset by $180^{\circ}$, the car body performs rotational vibration along the transverse axis, but it does not perform vibrations along the vertical axis. In order to "capture this problem", there have been defined the new values that are calculated based on the acceleration measured on the vehicle body and bogies frame, according the relationship:

$$
\begin{aligned}
& {\left[\begin{array}{l}
a_{\zeta 1} \\
a_{\zeta 2} \\
a_{\zeta 3} \\
a_{\zeta 4}
\end{array}\right]=\left[\begin{array}{cccc}
1 / 2 & 1 / 2 & 0 & 0 \\
1 / 2 & -1 / 2 & 0 & 0 \\
0 & 0 & 1 / 2 & 1 / 2 \\
0 & 0 & 1 / 2 & -1 / 2
\end{array}\right] \cdot\left[\begin{array}{l}
a_{z 1} \\
a_{z 2} \\
a_{z 3} \\
a_{z 4}
\end{array}\right]} \\
& {\left[\begin{array}{l}
a_{\varphi 1} \\
a_{\varphi 2} \\
a_{\varphi 3} \\
a_{\varphi 4}
\end{array}\right]=\left[\begin{array}{cccc}
1 / 2 & 1 / 2 & 0 & 0 \\
1 / 2 & -1 / 2 & 0 & 0 \\
0 & 0 & 1 / 2 & 1 / 2 \\
0 & 0 & 1 / 2 & -1 / 2
\end{array}\right] \cdot\left[\begin{array}{l}
a_{y 1} \\
a_{y 2} \\
a_{y 3} \\
a_{y 4}
\end{array}\right]}
\end{aligned}
$$

Where:

az1 - vertical acceleration measured at the accelerometer 1 (Fig. 4.0) az2 - vertical acceleration measured at the accelerometer 2 (Fig. 4.0) az3 - vertical acceleration measured at the accelerometer 3 (Fig. 4.0) az4 - vertical acceleration measured at the accelerometer 4 (Fig. 4.0) ay1 - lateral acceleration measured at the accelerometer 1 (Fig. 4.0) ay2 - lateral acceleration measured at the accelerometer 2 (Fig. 4.0) ay3 - lateral acceleration measured at the accelerometer 3 (Fig. 4.0) ay4 - lateral acceleration measured at the accelerometer 4 (Fig. 4.0)

Acceleration $a_{\zeta 1}$ is related to vertical vibrations of the car body, acceleration $\mathrm{a}_{\zeta 2}$ is related to the rotational along the lateral axis of the car body. Acceleration $\mathrm{a}_{\zeta_{3}}$ describes the consistent in phase vertical oscillation of bogies. And acceleration $\mathrm{a}_{\zeta 4}$ describes the opposite phase vertical oscillation of bogies.

Acceleration $a_{\varphi 1}, a_{\varphi 2}, a_{\varphi 3}$ and $a_{\varphi 4}$ correspond to analogue vibration in the lateral direction. Defined in this way accelerations are connected with corresponding vibration forms. Acceleration $a_{\zeta 1}$ and $a_{\zeta 3}$ are related to vertical car body oscillation (3 and 6 form of vibrations from the table 3.4). Accelerations $\mathrm{a}_{\zeta 4}$, and $\mathrm{a}_{\zeta_{2}}$ relate to the pitch (4 form of vibrations from the table 3.4). Similarly, for oscillation in a lateral direction, $\mathrm{a}_{\varphi 1}$ and $\mathrm{a}_{\varphi 3}$ are associated with top and bottom roll ( 1 and 5 of the form of vibrations from the table 3.4). In accordance to above information, values analyzed in order to detect failure in suspension are spectrum :Spectrum $a_{z}$, Spectrum $a_{z 2}$, Spectrum $a_{y 1}$, Spectrum $a_{y 2}$ and spectrum relations: Spectrum $a_{z 1} /$ Spectrum $a_{z 3}$, Spectrum $a_{z 2} /$ Spectrum $a_{z 4}$, Spectrum $a_{\zeta 1} /$ Spectrum $a_{\zeta 3}$, Spectrum $a_{\zeta 2} /$ Spectrum $a_{\zeta 4}$, Spectrum $a_{y} 1 /$ Spectrum $a_{y 3}$, Spectrum $a_{y 2} /$ Spectrum $a_{y 4}$, Spectrum $a_{\varphi 1} /$ Spectrum $a_{\varphi 3}$ and Spectrum $a_{\varphi 2} /$ Spectrum $a_{\varphi 4}$.

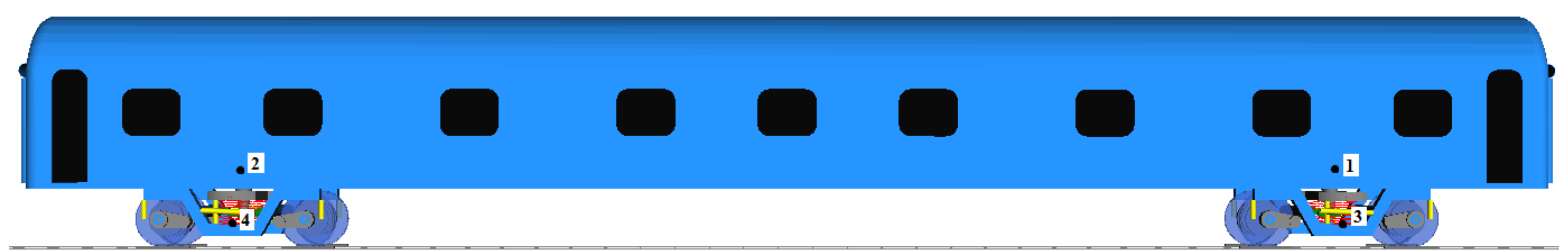

Fig. 2.1 Location of accelerometers on the vehicle 


\section{Analysis of results}

In the study used accelerometers fixed on the vehicle model. The authors made many simulations with different failure status. In particular simulations excluded different secondary dampers. The authors performed many runs with different conditions of track and different speed of run. Two accelerometers located on the car's floor directly on the bogies. The next two are inside of the bogie frame. These four sensors designed for dampers fault diagnosis.

Diagnoses made by compare spectrum from the car body and spectrum from the bogies. The solution prevents pollutions from track's irregularities.

Measured accelerations on the accelerometers are contaminated so not enough good to diagnose (Fig 2.1).

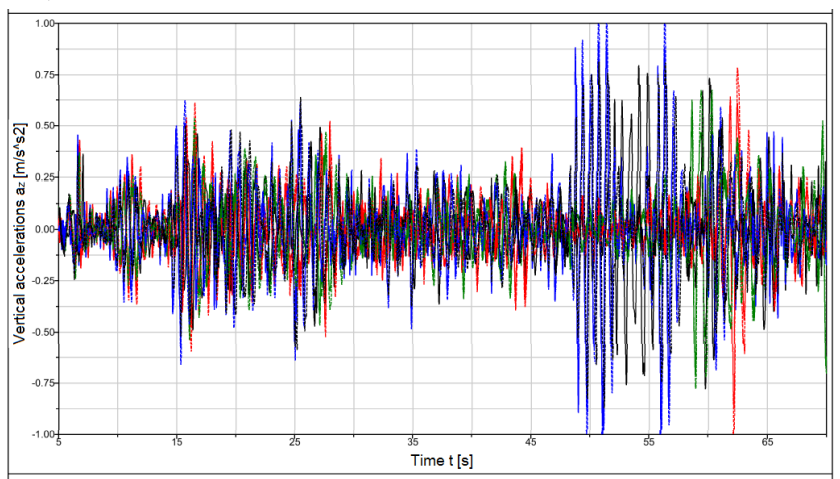

Fig. 2.1. Vertical accelerations from car body

It is necessary to apply Fourier analysis. Fourier analysis is use to extract the damage of dampers. Authors performed eight types of tests for vertical parameters:

1. Track 1, running speed $100 \mathrm{~km} / \mathrm{h}$, the passenger car was efficient and empty;

2. Track 1 , running speed $100 \mathrm{~km} / \mathrm{h}$, the passenger car was efficient and loaded;

3. Track 2, running speed $160 \mathrm{~km} / \mathrm{h}$, the passenger car was efficient and empty;

4. Track 2, running speed $160 \mathrm{~km} / \mathrm{h}$, the passenger car was efficient and loaded;

5. Track 1 , running speed $100 \mathrm{~km} / \mathrm{h}$, the passenger car was empty with damaged one vertical dumper;

6. Track 1, running speed $100 \mathrm{~km} / \mathrm{h}$, the passenger car was loaded with damaged one vertical dumper;

7. Track 2, running speed $160 \mathrm{~km} / \mathrm{h}$, the passenger car was empty with damaged one vertical dumper;

8. Track 2 running speed $160 \mathrm{~km} / \mathrm{h}$, the passenger was loaded with damaged one vertical dumper.

Weight of empty passenger car is $46 \mathrm{t}$, weight of loaded car is $59 \mathrm{t}$.

The results obtained for the vertical vibration show Table 2.1.
Table 2.1. Results obtained for the vertical parameters

\begin{tabular}{|c|c|c|c|c|c|c|}
\hline \multirow[b]{2}{*}{$\begin{array}{c}\text { Test } \\
\text { number }\end{array}$} & \multicolumn{6}{|c|}{ Maximal value (for: $\mathrm{f}<10 \mathrm{~Hz}$ ) } \\
\hline & $\begin{array}{c}\text { Spectrum } \\
\mathrm{a}_{z l} \\
{[\mathrm{~m} / \mathrm{s}]}\end{array}$ & $\begin{array}{c}\text { Spectrum } \\
\mathrm{a}_{z 2} \\
{[\mathrm{~m} / \mathrm{s}]}\end{array}$ & $\begin{array}{c}\text { Spectrum } \\
\mathrm{a}_{z l} / \\
\text { Spectrum } \\
\mathrm{a}_{23} \\
{[-]}\end{array}$ & $\begin{array}{c}\text { Spectrum } \\
\mathrm{a}_{22} / \\
\text { Spectrum } \\
\mathrm{a}_{24} \\
{[-]}\end{array}$ & $\begin{array}{c}\text { Spectrum } \\
\mathrm{a}_{\zeta \zeta t} / \\
\text { Spectrum } \\
\mathrm{a}_{\zeta 3} \\
{[-]}\end{array}$ & $\begin{array}{c}\text { Spectrum } \\
\mathrm{a}_{\zeta_{2}} / \\
\text { Spectrum } \\
\mathrm{a}_{\zeta 4} \\
{[-]}\end{array}$ \\
\hline 1 & 0,025 & 0,016 & 2,3 & 1,7 & 2,6 & 2,2 \\
\hline 2 & 0,027 & 0,018 & 2,8 & 1,8 & 3,4 & 2,5 \\
\hline 3 & 0,050 & 0,035 & 2,5 & 1,8 & 2,5 & 2,2 \\
\hline 4 & 0,040 & 0,035 & 2,7 & 2,1 & 3,6 & 2,4 \\
\hline 5 & 0,035 & 0,017 & 3,2 & 1,8 & 3,8 & 3,0 \\
\hline 6 & 0,035 & 0,022 & 4,3 & 2,0 & 4,4 & 3,4 \\
\hline 7 & 0,060 & 0,045 & 3,8 & 2,0 & 4,8 & 3,2 \\
\hline 8 & 0,050 & 0,048 & 3,8 & 2,5 & 4,0 & 3,3 \\
\hline
\end{tabular}

As shown in Table 2.1, the results from vertical spectrum accelerations are not satisfactory for detecting damages of vertical suspension elements. The results shown in Table 2.1 are close related to running speed.

Eight types of tests for lateral parameters:

1. Track 1, running speed $100 \mathrm{~km} / \mathrm{h}$, the passenger car was efficient and empty;

2. Track 1 , running speed $100 \mathrm{~km} / \mathrm{h}$, the passenger car was efficient and loaded;

3. Track 2, running speed $160 \mathrm{~km} / \mathrm{h}$, the passenger car was efficient and empty;

4. Track 2, running speed $160 \mathrm{~km} / \mathrm{h}$, the passenger car was efficient and loaded;

5. Track 1, running speed $100 \mathrm{~km} / \mathrm{h}$, the passenger car was empty with damaged two latera dumpers;

6. Track 1, running speed $100 \mathrm{~km} / \mathrm{h}$, the passenger car was loaded with damaged two lateral dumpers;

7. Track 2, running speed $160 \mathrm{~km} / \mathrm{h}$, the passenger car was empty with damaged two lateral dumpers;

8. Track 2 running speed $160 \mathrm{~km} / \mathrm{h}$, the passenger was loaded with damaged two lateral dumpers.

The results obtained for the lateral vibration show Table 2.2.

Table 2.2. Results obtained for the lateral parameters

\begin{tabular}{|c|c|c|c|c|c|c|}
\hline \multirow[b]{2}{*}{$\begin{array}{c}\text { Test } \\
\text { number }\end{array}$} & \multicolumn{6}{|c|}{ Maximal value (for: $0,8 \mathrm{~Hz}<\mathrm{f}<1,5 \mathrm{~Hz}$ ) } \\
\hline & $\begin{array}{c}\text { Spectrum } \\
\mathrm{a}_{y l} \\
{[\mathrm{~m} / \mathrm{s}]}\end{array}$ & $\begin{array}{c}\text { Spectrum } \\
\mathrm{a}_{y 2} \\
{[\mathrm{~m} / \mathrm{s}]}\end{array}$ & $\begin{array}{c}\text { Spectrum } \\
\mathrm{a}_{y l} / \\
\text { Spectrum } \\
\mathrm{a}_{y 3} \\
{[-]}\end{array}$ & $\begin{array}{c}\text { Spectrum } \\
\mathrm{a}_{y 2} / \\
\text { Spectrum } \\
\mathrm{a}_{y 4} \\
{[-]}\end{array}$ & $\begin{array}{c}\text { Spectrum } \\
\mathrm{a}_{\varphi 1} / \\
\text { Spectrum } \\
\mathrm{a}_{\varphi 3} \\
{[-]}\end{array}$ & $\begin{array}{c}\text { Spectrum } \\
\mathrm{a}_{\varphi 2} / \\
\text { Spectrum } \\
\mathrm{a}_{\varphi 4} \\
{[-]}\end{array}$ \\
\hline 1 & 0,019 & 0,019 & 1,29 & 1,65 & 3,01 & 1,38 \\
\hline 2 & 0,017 & 0,018 & 1,25 & 1,60 & 2,01 & 1,69 \\
\hline 3 & 0,020 & 0,021 & 1,22 & 1,65 & 2,32 & 1,44 \\
\hline 4 & 0,017 & 0,018 & 1,21 & 1,50 & 2,31 & 1,54 \\
\hline 5 & 0,028 & 0,028 & 1,90 & 2,20 & 4,17 & 2,09 \\
\hline 6 & 0,024 & 0,025 & 1,82 & 2,21 & 2,59 & 2,15 \\
\hline 7 & 0,027 & 0,028 & 1,81 & 2,22 & 3,40 & 2,03 \\
\hline 8 & 0,022 & 0,023 & 1,76 & 2,25 & 3,00 & 2,17 \\
\hline
\end{tabular}

The results confirmed previous assumptions about the inability of spectra of acceleration $a_{z 1}, a_{z 2}$ measured on the vehicle body to detect damage to vehicle suspension. As shown in the Table. 4.1 magnitudes are 
too heavily dependent on speed and used the track.

The relation Spectrum $a_{z 1} /$ Spectrum $\mathrm{a}_{\mathrm{z} 3}$ fig. 2.2 and Spectrum $a_{z 2} /$ Spectrum $a_{z 4}$ fig. 2.3 weakly depends on the speed and the condition of the track. For all rides with not active one secondary vertical damper are visible big increase Spectrum $a_{z 1} /$ Spectrum $a_{z 3}$. In this case, the increase ratio Spectrum $a_{z 2} /$ Spectrum $a_{z 4}$ is less pronounced. The reason for this behavior is the fact that the acceleration sensor 1 and 3 are located in close to a damaged damper. Based on these results it seems reasonable to specify border for failure damper on level (Spectrum $a_{z 1}$ /Spectrum $\left.a_{z 3}\right)_{\text {lim }}=0,3$ and (Spectrum $a_{z 2} /$ Spectrum $\left.a_{z 4}\right)_{\text {lim }}=0$,3. Similar properties characterized by relation Spectrum $a_{\zeta 1} /$ Spectrum $a_{\zeta 3}$ fig. 2.4 and Spec $a_{\zeta 2} /$ Spec $a_{\zeta 4}$ fig. 2.5, both of these values have sufficient insensitivity on the condition of the track, speed and changes in vehicle weight. The limit values for efficient damper can be assumed on level (Spectrum $a_{\zeta 1} /$ Spectrum $a_{\zeta 3}$ ) lim $=0.37$ and (Spectrum $a_{\zeta 1} /$ Spectrum $\left.a_{\zeta 3}\right)_{\text {lim }}=0,28$.

Summing up the results for vertical vibration, we can conclude that the relationship Spect $a_{z 1} /$ Spect $a_{z 3}$, Spectrum $a_{z 2} /$ Spectrum $a_{z 4}$, Spectrum $a_{\zeta 1} /$ Spectrum $a_{\zeta 3}$ and Spectrum $a_{\zeta 2}$ /Spectrum $a_{\zeta 4}$ characterized by insensitivity to change the state track and speed changes. These values are sensitive to changes in the parameters of the vehicle suspensions. These feature cause that these values are good to diagnostic state of suspension.

The situation is much more complicated for lateral vibration. The best diagnostic properties has the ratio of Spectrum $a_{\varphi 1} /$ Spectrum $\mathrm{a}_{\varphi 3}$ fig. 2,8 , because there is a clear boundary between failure state and the efficient state (Spectrum a 1/Spectrum a 3$)_{\text {lim }}=1,85$. A good diagnostic property is also the value Spectrum $a_{y 1} /$ Spectrum $a_{y 3}$ fig. 2.5 end Spectrum $a_{y 2} /$ Spectrum $a_{y 4}$ fig. 2.5. The value limit for the efficient state can be defined on level 1,7 for both ratio Spectrum $a_{y 1} /$ Spectrum $a_{y 3}$, Spectrum $a_{y 2} /$ Spectrum $a_{y 4}$.

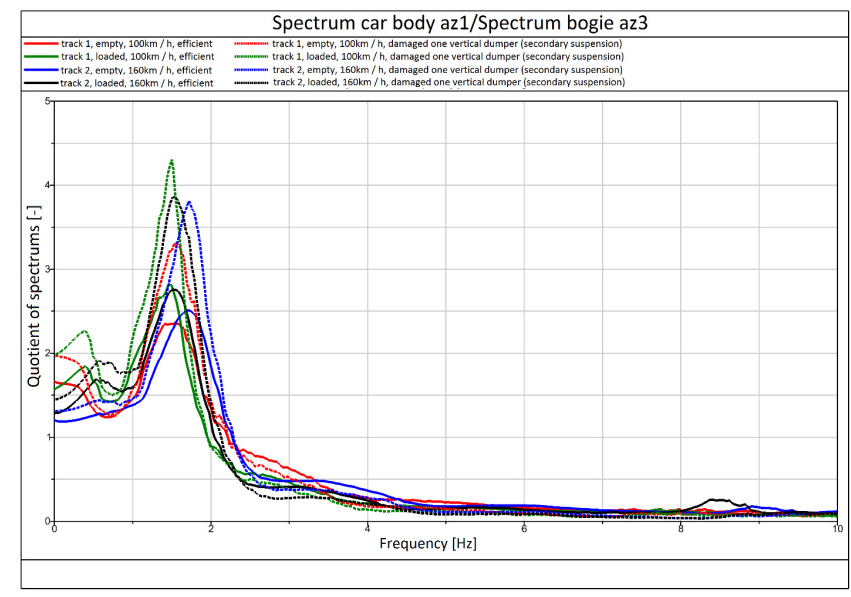

Fig. 2.2 Quotient of spectrum $a_{z 1}$ to spectrum $a_{z 3}$

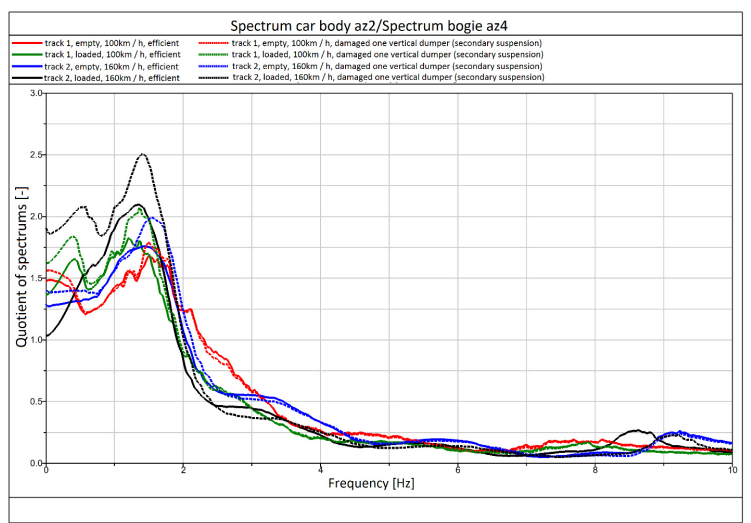

Fig. 2.3 Quotient of spectrum $\mathrm{a}_{\mathrm{z} 2}$ to spectrum $\mathrm{a}_{\mathrm{z} 4}$

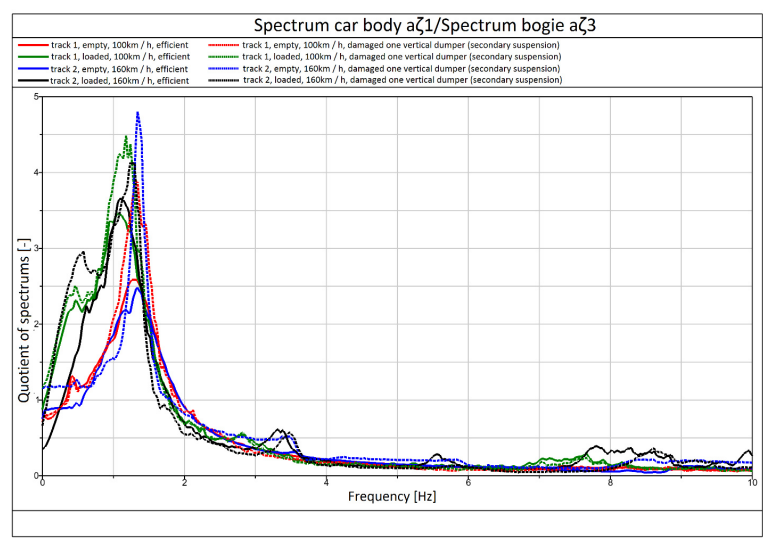

Fig. 2.4 Quotient of spectrum $\mathrm{a}_{\zeta 1}$ to spectrum $\mathrm{a}_{\zeta 3}$

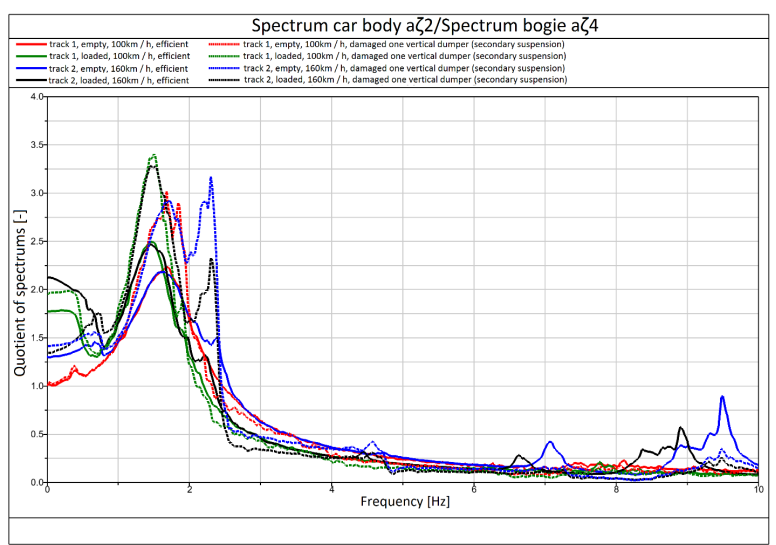

Fig. 2.5 Quotient of spectrum $\mathrm{a}_{\llcorner 2}$ to spectrum $\mathrm{a}_{\llcorner 4}$

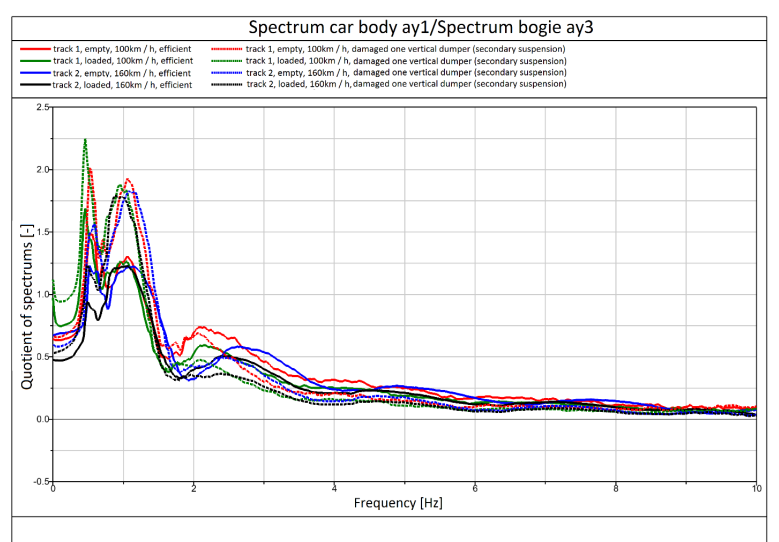

Fig. 2.6 Quotient of spectrum $\mathrm{a}_{\mathrm{y} 1}$ to spectrum $\mathrm{a}_{\mathrm{y} 3}$ 


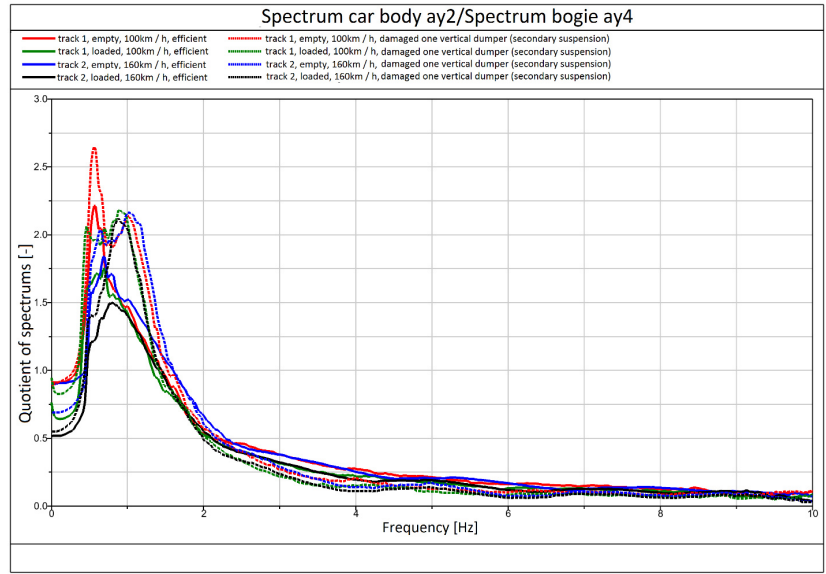

Fig. 2.7 Quotient of spectrum $a_{y 2}$ to spectrum $a_{y 4}$

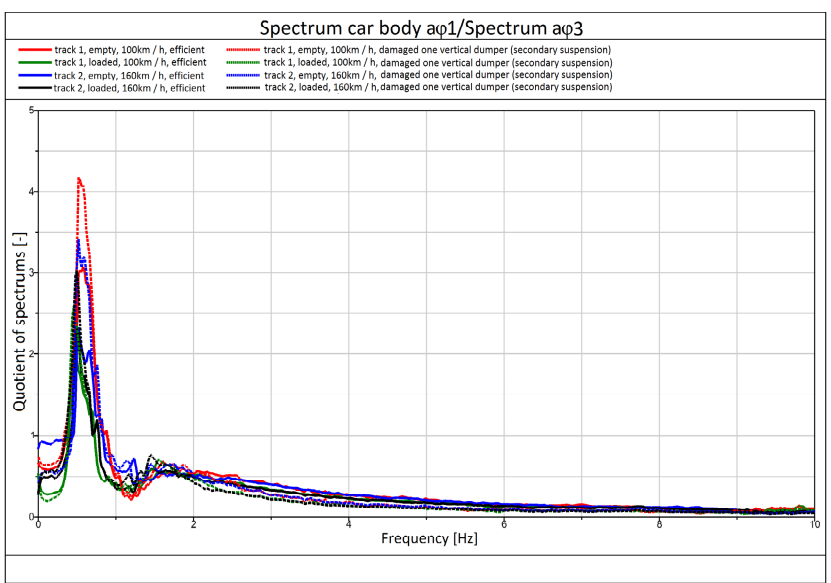

Fig. 2.8 Quotient of spectrum $\mathrm{a}_{\varphi 1}$ to spectrum $\mathrm{a}_{\varphi 3}$

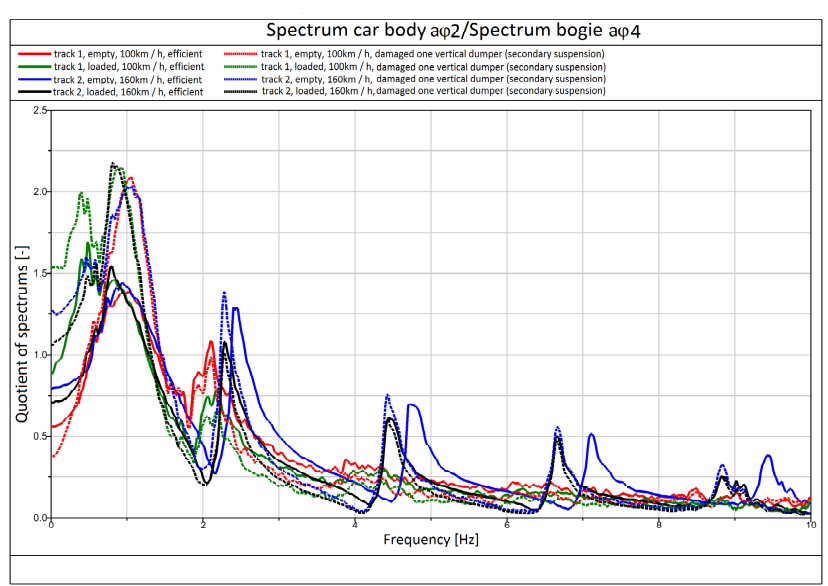

Fig. 2.9 Quotient of spectrum $\mathrm{a}_{\varphi 2}$ to spectrum $\mathrm{a}_{\varphi 4}$

\section{Conclusion}

The authors carried out simulation studies of railway vehicle to find diagnostic method for damages of suspension. Sixteen tests performed with different conditions. The simulation carried out for two types of track and at two running speeds. The most common failure of the passenger cars are dampers. Damages of the vertical and lateral dampers were introduced into the model.

Accelerations measured at accelerometers fixed on the car body and the bogie frames. The signals (accelerations) from accelerometers are not transparent. It is necessary to use Fourier analysis to ennoble the signal from accelerometers.

The results come from spectrum accelerations are often not satisfactory for detecting damages of suspension elements. The results are close related to running speed. The solution to this problem is the method described in this article. This method is based on a comparison of the spectrum acceleration measured on the car body with the spectrum measured on the bogie.

\section{REFERENCES}

[1] Suwalski Ryszard „Wózki 25AN i 25ANa do wagonów osobowych i typu osobowego" tts, lipiec 1994

[2] PN-EN 14363:2005 Kolejnictwo. Badania własności dynamicznych dla dopuszczenia (homologacji) pojazdów szynowych. Badania własności biegowych i próby stacjonarne. $2007 r$.

[3] Arczewski K.: Drgania uktadów fizycznych", Oficyna Wydawnicza Politechniki Warszawskiej, Warszawa 2008

[4] Freibauer L.:Dynamika kolejowych vozidel", NADAS, Praha 1991

[5] Hagel R.,,Miernictwo dynamiczne”, Wydawnictwo Naukowo-Techniczne, Warszawa 1975

[6] Osiński Z. „Teoria drgań”, Państwowe Wydawnictwo Naukowe, Warszawa 1980 